\title{
Recontextualização a serviço do desenvolvimento da escrita: análise de duas produções de texto do ensino médio
}

\author{
Recontextualization at the service of the writing development: \\ analysis of two text productions of high school
}

https://doi.org/10.34112/2317-0972a2019v37n76p125-145

\section{Tailane Flores Antunes ${ }^{1}$}

EDILAINE BUIN ${ }^{2}$

Resumo: Partindo do princípio de linguagem como interação e de texto como lugar em que ela se manifesta, pretende-se mostrar como a atividade de recontextualização, na produção textual, proporcionou aos estudantes refratarem acontecimentos discursivos. Trata-se de parte dos resultados de uma pesquisa-ação, no campo aplicado dos estudos linguísticos, cujos dados foram gerados em uma escola pública estadual, no município de Dourados/ MS, em dois primeiros anos do Ensino Médio. As aulas de Língua Portuguesa, que propiciaram a constituição do corpus composto por um total de 70 textos, envolveram leituras reflexivas e análise linguística de três versões do gênero conto de fadas Chapeuzinho Vermelho, culminando no trabalho de escrita/reescrita, pelos estudantes, da quarta versão do conto. Dois dos dados, qualitativamente selecionados, apontam que a materialidade dos contos recontextualizados pelos estudantes refrata experiências tanto empíricas quanto simbólicas e marca ideologias, crenças e valores. A atividade de recontextualização parece contribuir significativamente para o desenvolvimento da escrita, na medida em que propicia a concretização desta como acontecimento discursivo.

PalAVRAS-ChAVE: Recontextualização; acontecimento discursivo; aquisição da escrita.

1. Secretaria de Educação do Estado do Mato Grosso do Sul, Ponta Porã, MS, Brasil.

2. Universidade Federal da Grande Dourados, Faculdade de Comunicação, Artes e Letras, Dourados, MS, Brasil. 
Recontextualização a serviço do desenvolvimento da escrita: análise de duas...

ABSTRACT: Departing from both language's principle as interaction and text as a place in which it manifests itself, the current paper aims to show how recontextualization, in textual production, provided students to refract discursive events. This is part of the results of an action research, in the Linguistic Studies' applied field, whose data came from the first two years of high school of a state public school located at the city of Dourados/MS. The Portuguese language classes, which propitiated the formation of a corpus composed of 70 texts' total, involved reflective readings and linguistic analysis of three versions of the fairy tale genre "Little Red Riding Hood", culminating in the students' writing/rewriting work of the fourth version of tale. Two of the qualitatively selected data point out that the materiality of the stories recontextualized by students, refracts both empirical and symbolic experiences and brand ideologies, beliefs and values. The recontextualization activity seems to significantly contribute to the writing's development, as it promotes the accomplishment of this as a discursive event.

KEYWORDS: Recontextualization; discursive event; acquisition of writing.

\section{INTRODUÇÃO}

No atual cenário de ensino de Língua Portuguesa, em muitos contextos, a abordagem da gramática normativa ainda sobressai à reflexão sobre a língua(gem) e à prática de leitura e de escrita. De modo mais específico, encontramos recentemente tal realidade em uma escola pública de Dourados-MS, a qual conhecemos por meio do Projeto Institucional de Bolsas de Iniciação à docência (PIBID) ${ }^{3}$. Os dois primeiros anos do Ensino Médio (EM) eram descritos pela professora de Língua Portuguesa, a qual, na ocasião, era supervisora do Projeto, e pelos outros docentes da escola, como compostos por "estudantes que não gostavam, sabiam escrever" e "não escreviam".

Como parte do Projeto e, sobretudo, diante do desafio de evidenciar que a escrita se relaciona com a vida e, portanto, não há sentido em um estudante se negar a escrever, se essa relação for evidente, elaboramos uma sequência de ensino (CORDEIRO, 2015) com foco central na recontextualização. Em outras palavras, no nosso entendimento, os alunos se recusavam a fazer aquilo que se reduzia a "tarefa

3. Uma das autoras do artigo, na ocasião do desenvolvimento da pesquisa, era coordenadora do programa Institucional de Bolsas de Iniciação à Docência (PIBID), do curso de Letras da UFGD. A outra participou do programa como bolsista de graduação. Este projeto levou ambas ao desenvolvimento do trabalho de pesquisa, cujo resultado parcial vem descrito neste artigo. 
escolar". No entanto, se encontrassem um sentido maior na atividade e se houvesse algum envolvimento, a escrita fluiria. Para isso ocorrer, seria preciso trabalhar primeiramente um repertório - planejar uma situação em que tivessem o que e por que escrever. Como mostraremos adiante, encontramos a solução na recontextualização do conto de fadas Chapeuzinho Vermelho.

$\mathrm{O}$ recorte apresentado neste artigo, parte do desenvolvimento de uma pesquisa-ação, de base qualitativo-interpretativista ${ }^{4}$, envolveu, antes da escrita em si, leitura e análise linguística, voltadas para a construção de sentidos; e, posteriormente, a socialização do texto entre os colegas da mesma série. A sequência de ensino foi conduzida por uma das autoras ${ }^{5} \mathrm{e}$ acompanhada pela professora em serviço, participante da pesquisa. Cabe ressaltar que essa professora observou toda a sequência das atividades da proposta, esteve presente nas elaborações, intervinha nas explicações, contribuía com os alunos nas atividades de interpretação de texto e de análise linguística.

Os estudantes leram três textos literários: Chapeuzinho Vermelho (Charles Perrault), Chapeuzinho Vermelho (Irmãos Grimm) e Fita verde no cabelo (Guimarães Rosa). Depois de terem lido e interpretado as três versões e do tempo dedicado à discussão sobre os sentidos produzidos de acordo com as escolhas lexicais, sobre as intertextualidades e sobre outros elementos específicos de cada versão, foi solicitado que os alunos produzissem a quarta versão. Ou seja, que recontextualizassem o conto de fadas. Dado o envolvimento deles na atividade de escrita, a professora em serviço, que participou de todas as etapas da proposta, a partir dessa ação, incluiu os contos de fada (e outros textos literários) em suas atividades no Ensino Médio.

Trazemos 2, de 70 textos produzidos nessa situação de ensino, para compartilhar a experiência desses estudantes com a escrita. Partimos do pressuposto de que, quando a escrita é vivenciada como experiência, atrelada à vida, ou seja, como acontecimento discursivo, usando um termo de Corrêa (2007), os escreventes (em

4. Primeiramente a sequência de ensino, envolvendo conto de fadas e recontextualização, foi desenvolvida no âmbito do PIBID-Letras, pela bolsista graduanda, pela professora do Ensino Médio, ambas orientadas pela coordenadora de área do Programa. No ano seguinte, a bolsista ingressou no Mestrado e desenvolveu a mesma proposta, de forma mais aprimorada, em conjunto com a orientadora, coautora deste artigo. De certa forma, a experiência anterior serviu como um piloto que possibilitou uma nova forma de condução, em especial, em relação às análises linguísticas propostas e à forma de conduzir as reescritas. A professora do Ensino Médio que disponibilizou sua sala para a pesquisa era supervisora do PIBID e participou tanto do projeto piloto como deste aqui descrito.

5. A condução da sequência de atividades foi realizada pela autora que, na ocasião, era mestranda do Programa de Pós-Graduação em Linguística e Transculturalidade do curso de Letras da Universidade Federal da Grande Dourados (UFGD), orientada pela Profa. Dra. Edilaine Buin, coautora deste trabalho. 
especial aqueles cuja prática de escrita não faz parte das atividades familiares) parecem se debruçar mais naturalmente sobre essa atividade, sem tantas resistências. Nosso objetivo, neste artigo, é evidenciar isso, por meio da análise de dois dados representativos, selecionados qualitativamente, com base em uma quantificação prévia das ocorrências. Como o leitor poderá observar, a atividade linguística de recontextualização ocupa lugar central, pois, ao ter que deslocar algo/uma situação/ um episódio de um contexto para o outro, o escrevente tem que se posicionar histórica e culturalmente, fazendo-se existir na (e por meio da) escrita. Faz-se necessário acionar experiências reais ou simbólicas para elaborar seu texto.

Os pressupostos sobre dialogismo de Bakhtin $(1997,2006)$ e os modos de conceber a escrita e o ensino de escrita, postulados em Signorini (2001, 2006) e em Corrêa (2004, 2007) dão sustentação para as considerações. A noção de recontextualização, usada como base da atividade escolar proposta, foi inspirada em Kourilsky-Belliard (2004) e retomada em Dias (2002), Lira (2010) e Motta-Roth (2010). Sobre o gênero literário conto de fadas, tomamos como suporte Aguiar (2001), Bettelheim (2007), Coelho (1998), Góes (1991) e Propp (2006). Assim, a próxima seção ocupa-se em discutir tais pressupostos para, na seção seguinte, apresentarmos nossas análises.

\section{EM TORNO DA TEORIA}

Acreditamos que o ensino de escrita só acontece de fato quando permeado pela interação, pois concebemos a linguagem como prática social (BAKHTIN, 2006), negociada entre locutor e interlocutor envolvidos na interação, situados em um contexto sócio-histórico e cultural, por meio das práticas sociais. Nessa perspectiva, os sujeitos são vistos como agentes construtores e constituídos sócio-historicamente, e suas escolhas discursivas respondem sempre a outros já-ditos em circulação e apontam para enunciados futuros. Bakhtin (2006, p. 291) formula que todo enunciado (seja escrito ou oral) faz parte de "um elo da cadeia muito complexa de outros enunciados". Nesse sentido, concebemos o texto como a materialidade de um processo marcado pelas relações sociais dos envolvidos na interação.

Assim, qualquer texto é um ponto de uma cadeia linguística em fluxo. Nas palavras de Signorini (2001, p. 126), "a escrita é [...] uma fase de um processo contínuo de uma cadeia em fluxo: a das produções de linguagem que dão sentido e forma à realidade social". Se não fizer parte dessa cadeia, temos apenas um amontoado de palavras e expressões. Toda a escrita se constitui heterogeneamente, como postula 
Corrêa (2004, 2007): "é o resultado do trânsito entre práticas orais e letradas. Ao mesmo tempo em que a escrita é, portanto, reflexo e gênese das relações interativas, nela são refratadas ${ }^{6}$ situações concretas das relações de interação representadas no texto, que denunciam 'uma retomada de relações sociais"' (CORRÊA, 2004, p. 129).

Entendendo a escrita como heterogeneamente constituída, não faz mais sentido apenas tratá-la como objeto a ser adequado, seja ao gênero discursivo, seja à norma padrão, comum ao tratamento que é dado ao texto dos aprendizes da escola em foco e das escolas em geral. O texto, incluindo o do aprendiz, é reflexo "[...] de experiência - tanto no sentido da novidade que toda reapresentação da experiência traz, quanto no sentido de retomada do já experimentado, o que permite entender experiência também como memória" (CORRÊA, 2007, p. 204). Essa memória diz respeito ao já vivenciado empiricamente e ao vivenciado simbolicamente: o visto, o já dito e o lido (as vozes) de que o escrevente se apropria e recontextualiza em sua escrita, por meio das estratégias, de escolhas linguísticas e de vozes que refletem, no discurso, o modo como interpreta a realidade e a forma como reconstrói determinado contexto. Desse modo, na situação escolar apresentada, o conto de fadas possibilitou, como veremos, a retomada do já experimentado na construção do novo de cada estudante.

Para cumprir o objetivo de que os estudantes (que não escreviam, segundo a professora e as coordenadoras da escola) produzissem um texto, precisávamos tirar de foco a materialidade do texto para priorizarmos a sua discursividade: dar voz aos estudantes e, sobretudo, ouvi-los. Para isso, partimos da atividade de recontextualização: atribuição de novos significados a algo já existente. Segundo estudos da psicologia, $o$ ato de recontextualizar envolve um conjunto de situações de escrita e circunstâncias "relativo ao momento de leitura e respectiva interpretação dada pelos diferentes leitores" (LIRA, 2010, p. 132), por isso, sua base é a consideração das realidades subjetivas que se articulam, ao mudar o olhar para/em determinado contexto (KOURILSKY-BELLIARD, 2004).

A atividade de recontextualizar implica o deslocamento de um texto para um contexto sócio-histórico e cultural, diferente do anterior, o que nos permite defender que "[...] os discursos são ressignificados a partir dos lugares de fala ou de escrita que vão influenciar fortemente seu momento de produção" (LIRA, 2010, p. 51). Confirma, assim, Dias (2004, p. 3):

6. Nossa concepção de refratar decorre de Bakhtin (2006). Ele considera o refletir e o refratar como processo pelo qual o signo ideológico passa. Refratar é quando o signo que possui um significado passa a ter outros exteriores, a refratar outras realidades. 
Recontextualização a serviço do desenvolvimento da escrita: análise de duas...

Também podemos dizer que o processo de recontextualização caracteriza-se por um movimento de textos e de seus contextos, originais ou não, para outros contextos no qual esses discursos passam a constituir uma nova ordem e um novo sentido. Nesse processo de recontextualização, portanto, a partir do novo contexto em que o discurso se insere, passa também a adquirir um novo significado, mesmo que ele esteja fortemente relacionado a outros tempos e espaços.

Embora um texto seja único em si, quando deslocado para outro contexto, ou apropriado por alguém, é incorporado à visão subjetiva de cada um, sob influência do contexto em que esse está inserido no momento.

Entendemos, contudo, que o escrevente está permeado por história, vozes e valores. Nesse sentido, vale mencionar o trabalho de Motta-Roth (2010), que, em um estudo no campo aplicado da Linguística, sobre a popularização da ciência a partir dos gêneros e da recontextualização, demonstra que o dialogismo e a intertextualidade são intrínsecos a esse fenômeno, bem como ao funcionamento do discurso. Assim, recontextualizar funciona como um descolamento não apenas de texto, mas - e principalmente - de vozes, de ideologias e de percepções de mundo.

Essas relações dialógicas se constituem por experiências, tanto empíricas (vivenciadas e vistas na prática do dia a dia) quanto simbólicas (conhecidas por meio dos livros e das mídias) e se manifestam nas relações interativas, podendo se concretizar na escrita. Isso, por sua vez, marca o caráter heterogêneo, de muitas vozes, e configura a escrita como um acontecimento discursivo (Corrêa, 2007) de vivências de cada escrevente, em diferentes contextos.

\subsection{EXPERIÊNCIAS SIMBÓLICAS}

Pensando tanto na recontextualização quanto na escrita como acontecimento discursivo, apostamos no trabalho com o gênero literário conto de fadas, como experiência simbólica, pelo fato de ser milenário, recontextualizado inúmeras vezes, carregado pelas ideologias, pelos costumes e pelas crenças de cada época histórico-cultural, além de seu poder humanizador, inerente aos textos literários. Além disso, faz parte do conjunto de textos para os quais os Parâmetros Curriculares Nacionais (PCN) dão visibilidade. $\mathrm{O}$ documento propõe que a disciplina Língua Portuguesa seja: 
[...] um trabalho de produção de conhecimento, organizado por ações de leitura, escrita, escuta e socialização de saberes (informação), a ser orientado e avaliado contínua e permanentemente pelo(s) professor(es). Sob uma orientação interdisciplinar, podem-se eleger estudos sobre as narrativas do domínio literário; as narrativas dos grandes feitos históricos (locais, regionais, nacionais); as narrativas do universo oral (da cultura popular); as narrativas do mundo midiático (imprensa, TV e rádio); as narrativas do universo mítico; as narrativas do mundo bíblico (BRASIL, 2006, p. 27-28, grifos nossos).

O gênero conto de fadas não está marcado explicitamente nos nossos parâmetros, mas ele pode ser considerado, segundo Coelho (1998), como narrativa popular do universo oral que integra a categoria das narrativas do domínio literário. E, por outro lado, de acordo com Todorov (1970), pode ser classificado também como sendo do mundo maravilhoso, das narrativas maravilhosas:

No caso do maravilhoso, os elementos sobrenaturais não provocam qualquer reação particular nem nas personagens nem no leitor implícito. Não é uma atitude para os acontecimentos contados que caracteriza o maravilhoso, mas a própria natureza desses acontecimentos. Os contos de fadas e a ficção científica são algumas das variedades do maravilhoso. (TODOROV, 1970, p. 160)

O conto de fadas surgiu a partir das narrativas orais na Antiguidade, e só no século XVII, na França, é que foi transcrito por Charles Perrault e tornou-se público. $\mathrm{Na}$ época, os textos eram direcionados aos adultos:

Na idade Média, sua função era de expressar, de forma simbólica, os conflitos dos camponeses [...] com os senhores feudais [...] Mas, à medida que a sociedade ia se transformando e surgia uma nova classe social [...] os contos de fadas começaram a ser recontados para as crianças das novas famílias. (AGUIAR, 2001, p. 79-80)

Só dois séculos depois, preocupados em recuperar o tronco linguístico europeu, e com início dos estudos de Gramática Comparativa, é que os irmãos Jacob e Wilhelm Grimm recolheram os acervos da memória cultural, entre eles os contos de fadas. E na imensidão de repertório para o estudo das línguas, os irmãos se encantaram, "redescobrem o mundo maravilhoso da fantasia e dos mitos que desde sempre seduziu 
a imaginação humana" (COELHO, 1998, p. 73) e resolveram recontextualizar o conto de fadas para o contexto em que se situavam, publicando-os.

Por isso, por ser munido por histórias, contextos e recontextos que fazem parte de uma rede maior, de relações tecidas por fios ideológicos; por visões de mundo; por justificativas históricas; por estratégias; e por acontecimentos, é que a escolha pelo gênero conto de fadas se justifica. Não se trata de um objeto ingênuo e superficial, como é visto pelo senso comum. Mas de um texto envolto por fios que tecem a "[...] materialidade dos acontecimentos, que é a do sentido, guardada não só no que está posto no texto, mas também nos 'implícitos' de que sua leitura necessita" (PÊCHEUX, 1999, p. 5 apud CORRÊA, 2007, p. 206).

Apesar da forma e da estrutura simples (que, por estratégia, facilita o acompanhamento do enredo por todos), tais textos apresentam uma temática humana que promove o acesso à realidade $\mathrm{e}$ "[...] facilita a ordenação das experiências existenciais do sujeito" (AGUIAR, 2001, p. 77). De acordo com Coelho (1998, p. 13), a base de um conto é a problemática existencial, e a "efabulação básica do conto de fadas expressa os obstáculos ou provas que precisam ser vencidas, como um verdadeiro ritual iniciático, para que o herói alcance sua auto realização existencial”.

Segundo Góes (1991), o cenário dessas narrativas configura-se, geralmente, como florestas encantadas ou um castelo maravilhoso. Já entre os personagens, geralmente há animais encantados, que são transformados em gente ou sofrem ação contrária. Há, especialmente, crianças ou jovens em idade de casar que assim se caracterizam:

Ou são excessivamente boas ou medrosas, belas ou tragicamente feias, ou perversas ou covardes, ou valentes e nobres; ou são anõezinhos, ou gigantes, bruxas ou princesas, reis disfarçados de mendigos ou mendigos convertidos em reis e cavaleiros. (GÓES, 1991, p. 116)

Outro fato que observamos nos contos, em geral, é a presença marcante dos verbos no pretérito imperfeito, de uma história passada que sobrevive ainda hoje, no tempo presente. Propp (2006), um formalista russo, também analisou os contos em relação a sua composição e construção, a partir dos tipos de personagens e suas funções. Segundo o autor (1983, p. 16-17), as funções são 31, que, em suma, vão desde o afastamento da família por um dos membros, até a função em que o agressor é punido e o herói se torna feliz para sempre. 
Propp (2006) cita e explica as funções uma a uma, além de estabelecer sete tipos de personagens mais comuns nos contos: o herói, a princesa, o antagonista, o doador, o auxiliar, o mandante e o falso herói. Conforme constatado, talvez não apareçam todos no mesmo conto, mas sempre irá existir um - ou mais - desses personagens citados. Assim, foi pela junção do discurso e da sua estrutura singular que o gênero conto de fadas foi por nós escolhido para ser trabalhado em sala de aula.

Portanto, partindo da proposição de que "o dinamismo que marca a relação do sujeito com a linguagem” (CORRÊA, 2004, p. 209) é caracterizado e constituído na interação com outros já ditos, com diferentes contextos e experiências, pretendemos mostrar evidências, no texto dos estudantes em foco, de como o conto de fadas, aliado à leitura de mundo e à possibilidade de "escrever" essa mesma leitura, pode auxiliar para que esse dinamismo se faça presente na escola e colabore para o desenvolvimento da escrita. Partimos do pressuposto de que o conto de fadas, por ser imbuído de sentido e motivado pelas relações sociais (BETTELHEIM, 2007; COELHO, 1998), pode funcionar como gênero catalizador (SIGNORINI, 2006) do desenvolvimento da escrita na escola. Ao recontextualizá-lo, o aprendiz traz à baila seu ponto de vista sobre o mundo, sobre sua história. Desse modo, a escrita, longe de ser material para adequação - limitado ao conjunto de tarefas escolares -, amplia-se como reveladora de acontecimentos discursivos (CORRÊA, 2007).

\section{O QUE OS DADOS REVELAM}

A atividade decorrente do trabalho com a leitura - a análise linguística e a (re) escrita que aconteceram em dois primeiros anos do Ensino Médio - partiu do comando para que os estudantes, depois de terem lido três versões do conto de fadas Chapeuzinho Vermelho, produzissem a quarta versão. A pesquisa, da qual este artigo expõe uma pequena parte, contou com um total de 70 textos, que passaram, primeiramente, por uma análise quantitativa, em que foram agrupados em 4 categorias, por sua predominância: categoria o1: casos em que o escrevente conta outra história e só cumpre a tarefa; categoria 02: casos em que brinca, ironiza o texto; categoria 03: casos em que moraliza ou torna o enredo mais ingênuo; e categoria 04: casos em que o texto se configura mais verossímil, e os elementos linguísticos da narrativa, mais bem articulados. $\mathrm{O}$ esquema a seguir ilustra isso: 
Recontextualização a serviço do desenvolvimento da escrita: análise de duas...

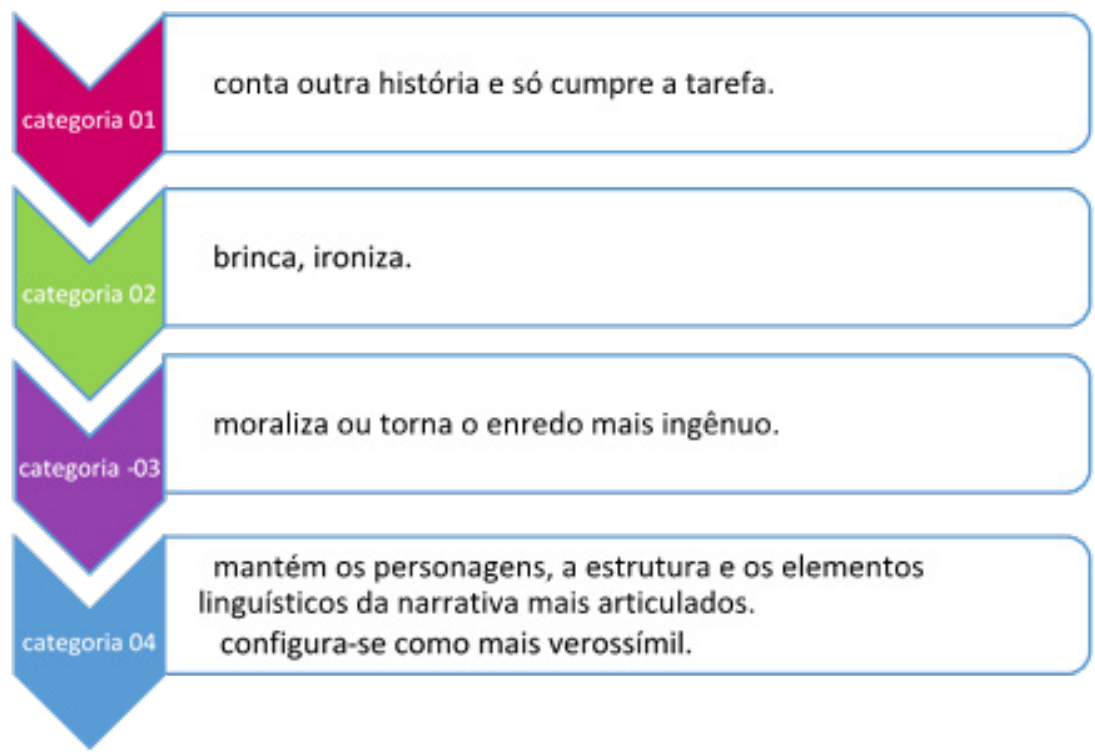

Figura 01: Esquema de categorização - Fonte: Dados da pesquisa

O gráfico a seguir consegue demonstrar e sintetizar, quantitativamente, em que proporção e como os estudantes recontextualizaram seus próprios contos:

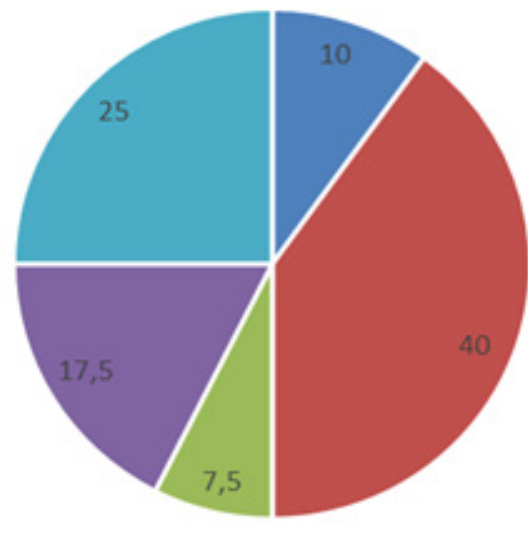

= fuga = categ. 01 = categ. 02 = categ. 03 " categ. 04

Gráfico o1: Categorizações em porcentagem - Fonte: Dados da pesquisa 
O gráfico demonstra, em relação às categorias de análise, que $10 \%^{7}$ (categoria 01) dos escreventes fogem totalmente da proposta de produção escrita, como se não houvesse acontecido o ciclo de leitura, a construção de sentidos e a análise linguística em sala de aula; a maioria, 40\% (fuga), utiliza a tarefa de recontextualizar apenas como um pretexto para contar uma outra história, tendo como predominância a temática da sexualidade e da violência; $25 \%$ (categoria 04) das produções representam a predominância dos personagens antigos, reconstruídos e articulados, em um texto mais verossímil; 17,5\% (categoria 03) dizem respeito às produções caracterizadas como mais ingênuas e moralizantes, bem próximas às versões lidas; e 7,5\% (categoria 02) dos textos se configuram na tentativa de tirar a seriedade do conto lido, satirizando-o. Cada categoria se configurou a partir de aspectos gerais recorrentes em cada grupo e elas foram inspiradas, em um viés transdisciplinar, em Kourilsky-Belliard (2004), que tematiza a recontextualização, ao falar das necessidades terapêuticas de pacientes mudarem o ponto de vista conceitual ou perceptual.

Depois de tabeladas as categorias, os dados representativos foram analisados a partir da metodologia de base qualitativo-interpretativista, o que nos permitiu estudar nosso objeto, buscando "dar conta da pluralidade de vozes em ação no mundo social e considerar que isso envolve questões relativas a poder, ideologia, história e subjetividade" (MOITA LOPES, 1994 apud APARÍCIO, 2014, p. 91). Nosso olhar, vale reforçar, atentou-se ao modo como os estudantes recontextualizaram os contos lidos em sala de aula e como os elementos linguísticos das versões lidas anteriormente e trabalhados em sala de aula se manifestaram nos textos deles.

Ponderamos que não há limite preciso entre uma categoria e outra: cada uma agrupa textos cujas características comuns são evidentes. Dois do conjunto de dados compõem este artigo: um representante da categoria $02 \mathrm{e}$ outro da categoria 04 . Escolhemos para este artigo dois contos pertencentes às duas categorias que reúnem aqueles que cumpriram a orientação da proposta, mais próximos do que era esperado pelas professoras pesquisadoras, ou seja, que de fato eram recontextualizações evidentes (e não o desenvolvimento de outra história, categoria 1; ou uma moralização e simplificação do enredo, categoria 3 ). A seguir, em 3.1 e 3.2, cada um dos dados.

7. Essa porcentagem contabilizada é representativa de alguns alunos, que fogem totalmente do gênero e da proposta de escrita. Nós não a consideramos como uma categoria, pois não se configura como uma recontextualização. Há um caso, por exemplo, em que, só para sair da sala de aula e entregar a atividade, o aluno escreve uma notícia inspirada em um fato do cotidiano, sem qualquer relação com a atividade proposta. 
Recontextualização a serviço do desenvolvimento da escrita: análise de duas...

3.1. A SÁTIRA E O HUMOR

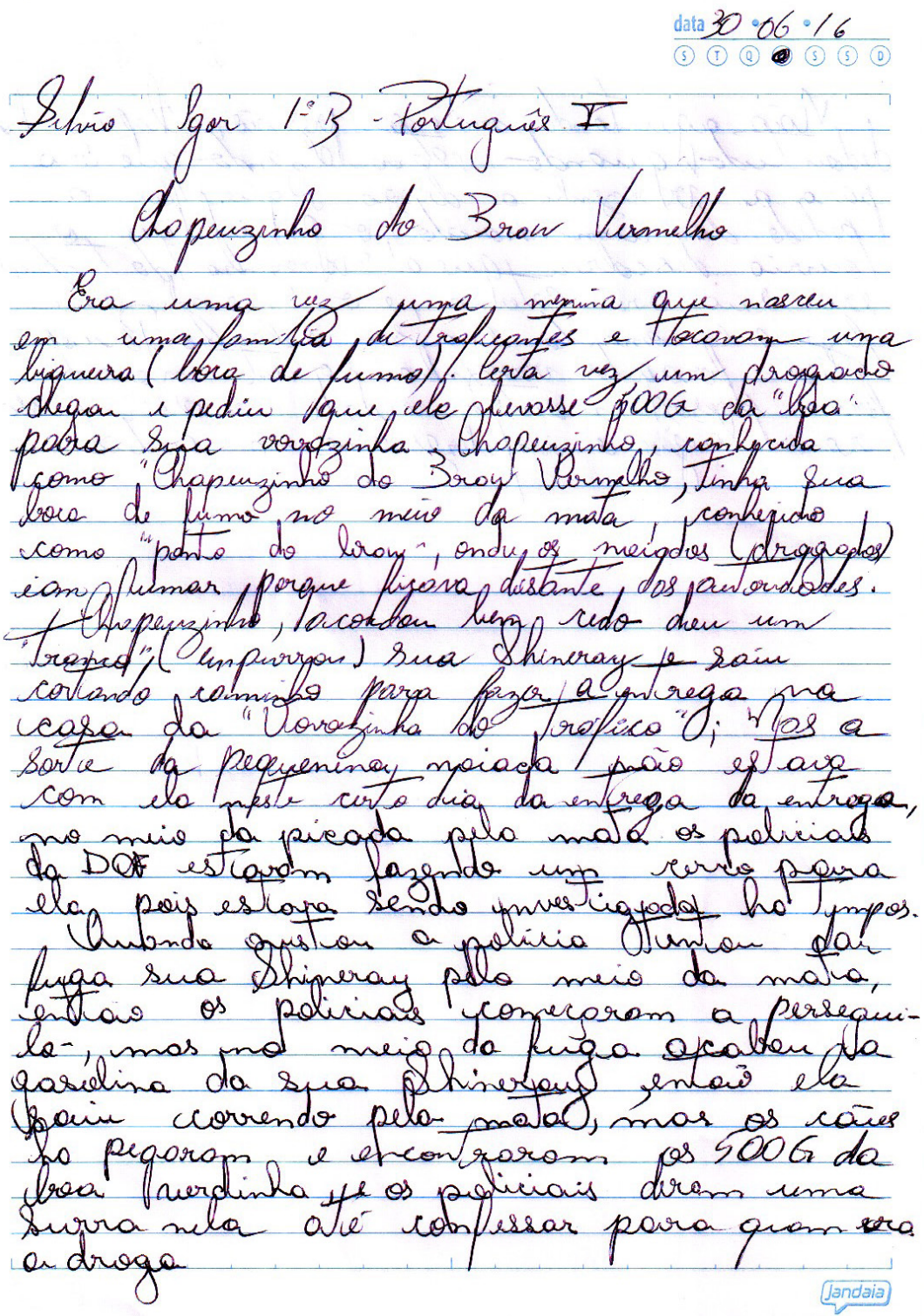




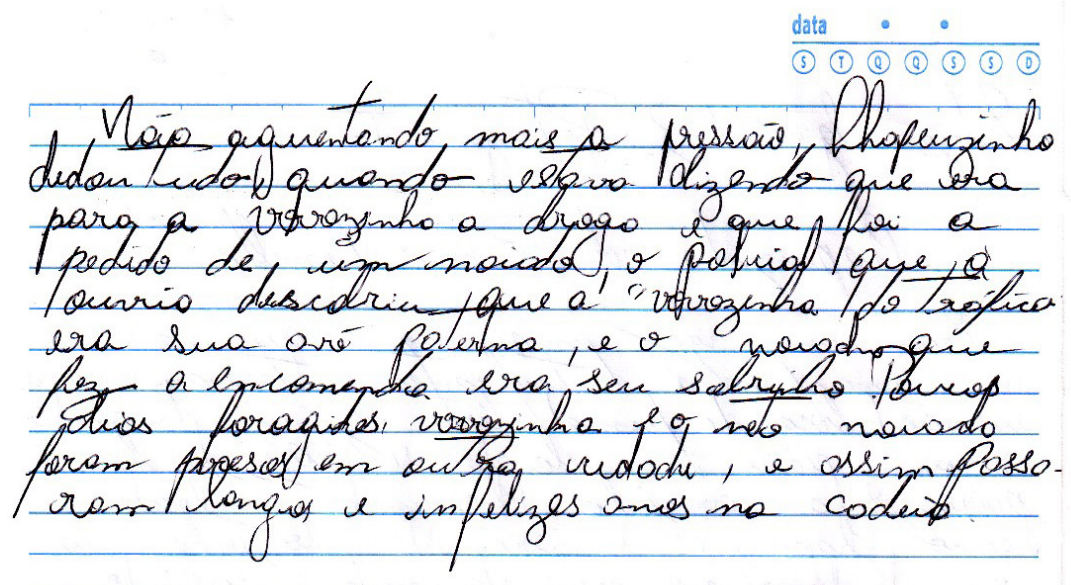

Figura 05: segunda versão do estudante João, $1^{\circ}$ ano B do EM - Fonte: Dados da pesquisa

Este recontexto de Chapeuzinho Vermelho, produzido pelo estudante João ${ }^{8}$, do primeiro ano do Ensino Médio, traz muitas marcas do enredo "original", mas também tece muito do contexto atual em que estamos imersos, ou seja, refrata seu cotidiano e suas ideologias vivenciadas, seja empírica ou simbolicamente.

O escrevente coloca as personagens do conto no contexto do tráfico de drogas. O movimento que, outrora, era de levar a cesta de doces até a casa da vovozinha, desta vez, na recontextualização, é substituído por outro: levar $500 g$ da boa. Apesar de o conteúdo da história se assemelhar a uma notícia jornalística, João utiliza-se da estrutura típica do conto de fadas, em que o título é o nome da personagem da história lida e o era uma vez, o bosque, a mata e a vovozinha mantêm-se e se relacionam na direção de brincar com a questão do tráfico de drogas.

Nessa produção, a questão central, que também entra em cena em $40 \%$ do total delas, o problema das drogas confirma a escrita como um acontecimento discursivo (CORRÊA, 2007), de experiências simbólicas (adquiridas pelos jornais televisivos) e vivências. Percebemos, na leitura do texto, que nos conduz a construir sentidos, muito do que este estudante possa ter vivido ou ouvido. A escolha da Shineray, por

8. Para preservar a identidade dos estudantes, escolhemos um nome fictício para cada um.

9. O original vem entre aspas porque há muitas versões e adaptações do conto, há anos. Desse modo, torna-se difícil saber qual é a obra original. 
Recontextualização a serviço do desenvolvimento da escrita: análise de duas...

exemplo, justifica-se pelo fato de ser uma moto consideravelmente barata e que não precisa de habilitação para ser conduzida, bastante cobiçada entre os jovens e bastante lembrada, até nas músicas escutadas por eles. E a narrativa, apesar de, a princípio, parecer inocente ou causar estranheza, faz-se coerente, porque a lógica dos acontecimentos consegue dar indícios do que o escrevente quis contar ao leitor.

Constatamos que os ditos no texto revelam intenção e ação sobre o outro (BAKHTIN, 1997). Quando, por exemplo, João utilizou gírias, tais como brow, biqueira, da boa, noiados, tranco, picada, cerco, verdinha e dedou, foi solicitado, na correção, que trocasse as palavras ou informasse ao leitor o significado dessas expressões. Então, ele optou por explicar, nos parênteses, o significado de cada uma para a professora, mantendo as gírias e o tom bem-humorado, já que seu público-alvo era formado por seus próprios colegas, os quais, certamente, entenderiam a realidade narrativa.

João interpreta satiricamente a realidade dos traficantes, como uma espécie de "aventura" pela qual passam, mas, ao final, são apreendidos, o que também indica uma mudança e/ou reformulação do posicionamento (KOURILSKY-BELLIARD, 2004) do escrevente. Tendo em vista que suas atitudes não eram "boas" e, nas "boas histórias", no final, o bem sempre vence o mal, João faz uma analogia com o "foram felizes para sempre", colocando os personagens na cadeia, como forma de castigo para o que fizeram, e relatando que viveram infelizes anos lá.

A recontextualização (KOURILSKY-BELLIARD, 2004) também permite pensar sobre algum assunto ou "problema", colocado em outro contexto, e descobrir nele um lado positivo, ou outra forma de resolvê-lo. Neste caso, o estudante parte de um evento comum na mídia, o tráfico de drogas, e traz a personagem principal do contexto anterior, Chapeuzinho Vermelho, como a chefe, uma menina inconsequente que "só está fazendo seu trabalho". O escrevente coloca todos aqueles personagens que estão comercializando drogas como parentes do policial, ou seja, alega que até o policial tem familiares envolvidos com tráfico, compradores/usuários de entorpecentes. E, para minimizar a problemática, João coloca-os em outra cidade como foragidos, para que o policial não tenha que prender os seus.

Desse modo, o estudante (re)elabora, na recontextualização, a problemática com o tráfico de drogas para livrar o personagem da situação constrangedora de ter que prender seu(s) próprio(s) familiar(es). Coloca a vovozinha do tráfico e o seu neto em um contexto de corrupção e sátira e com elementos do conto de fadas recontextualizados para atingir seu objetivo a partir, também, de suas subjetividades e vivências. 
Exposto e analisado o primeiro dado, a seguir apresentamos o segundo, da estudante Ana, do mesmo primeiro ano do EM.

\subsection{A ALTERNÂNCIA DE PAPÉIS}

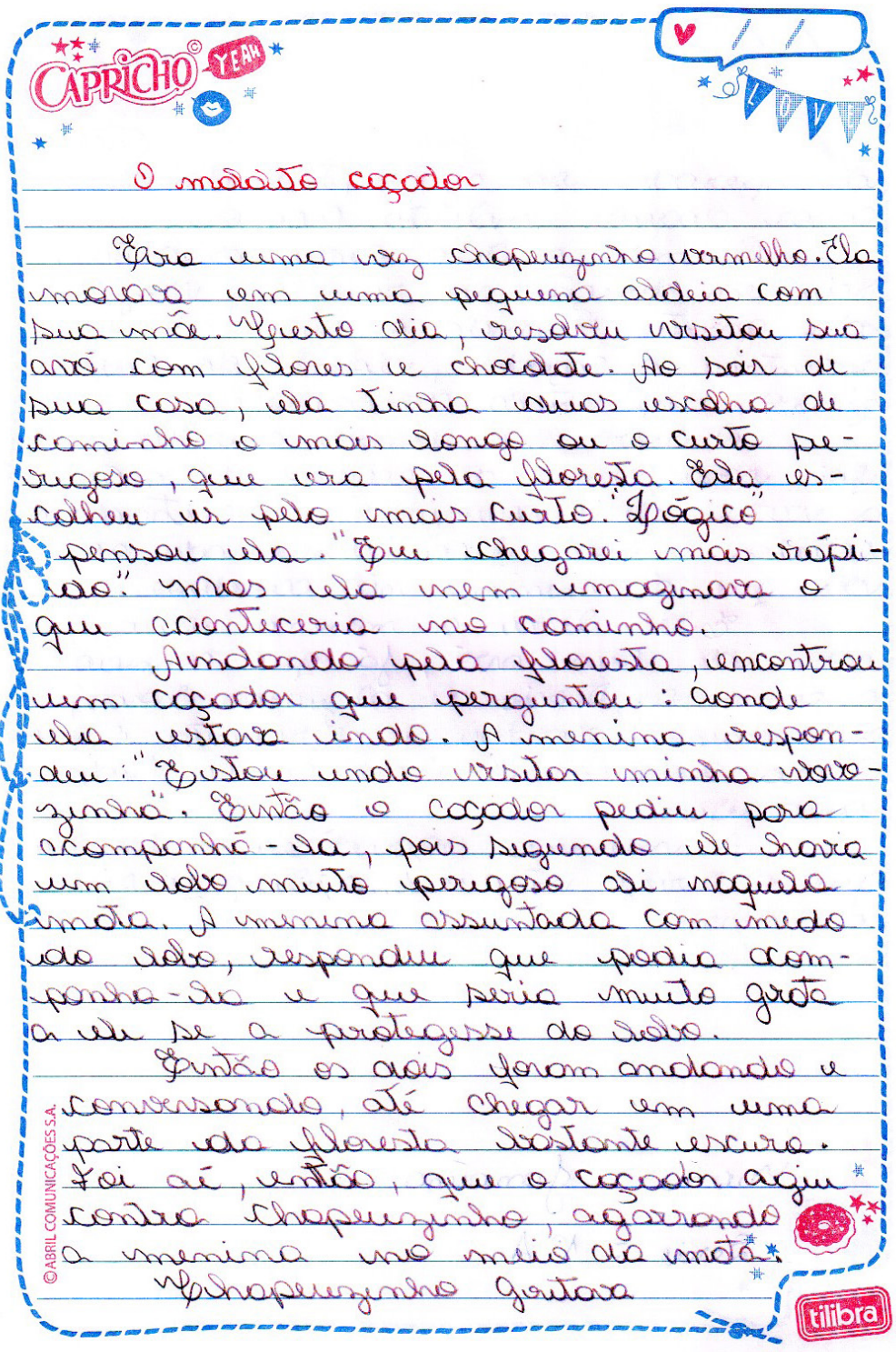


Recontextualização a serviço do desenvolvimento da escrita: análise de duas...

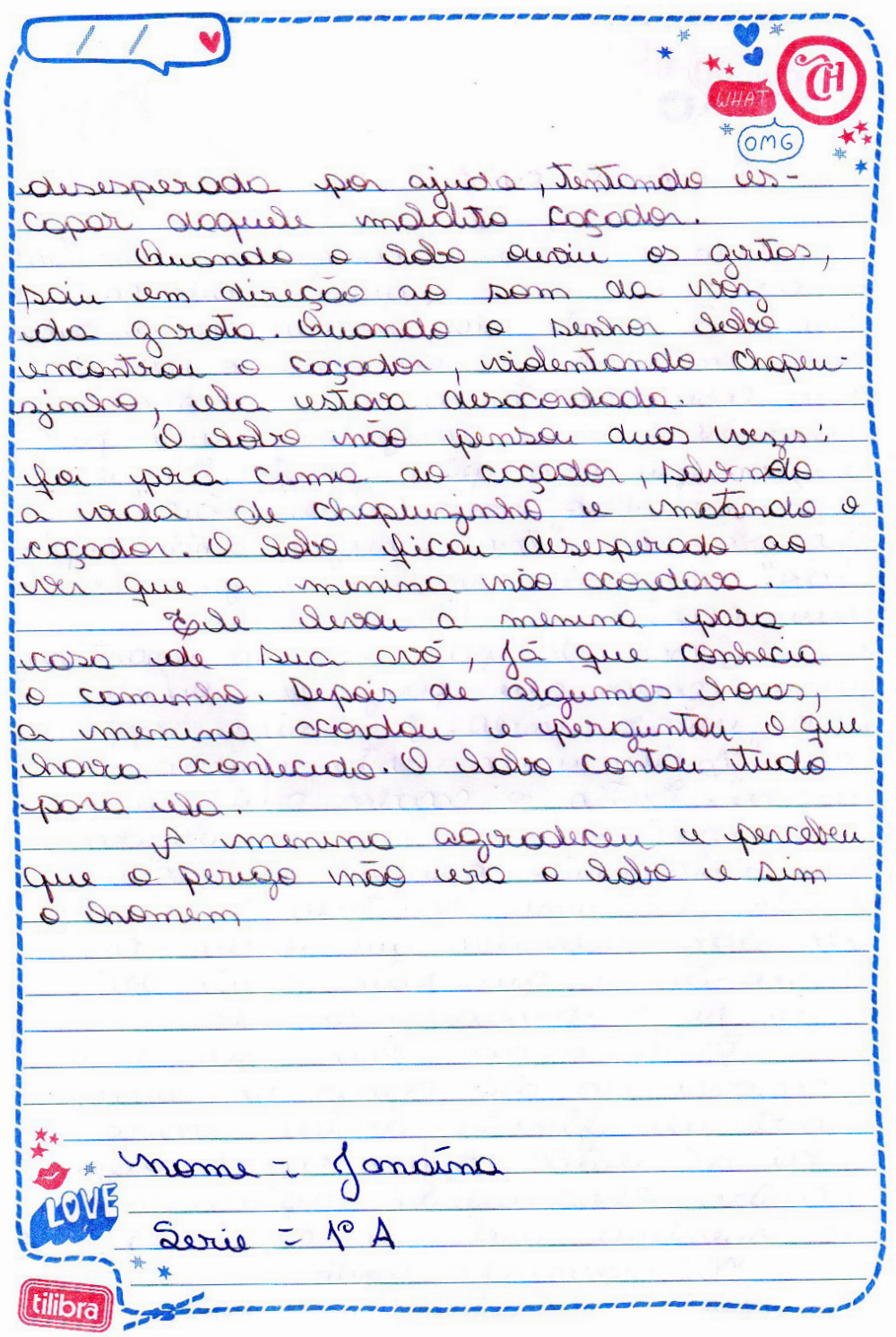

Versão da estudante Ana, $1^{\circ}$ ano A do EM - Fonte: Dados da pesquisa

Esta produção textual, da estudante Ana, carrega bastantes indícios da atividade de recontextualização da versão de Perrault do conto de fadas de Chapeuzinho Vermelho: a retomada do era uma vez, da aldeia em que a menina morava com sua 
mãe; o episódio da visita à avó (mas que, dessa vez, era para levar flores e chocolate); o caminho pela floresta; e o próprio lobo.

É possível verificar, por meio dos aspectos linguísticos, como os sentidos se constroem: a escrevente, logo no início do texto, traz um narrador onisciente, o qual funciona como a consciência da personagem, que pensa por ela e pela memória do conto lido e prevê o que encontraria no caminho: "o caminho mais longo ou o curto perigoso", mas, ainda assim, relata que a personagem resolve que o caminho mais curto e mais rápido é o que ela deseja fazer.

Nessa nova história, o reflexo daquela lida anteriormente foi refratado de outra forma, conforme o universo da escrevente. O lenhador é trocado por um caçador, que aborda a menina em seu caminho para a casa da avó e deseja ajudá-la, assim como na moral do conto de Perrault, em que os "bons moços" se oferecem para acompanhar as moças. Diferentemente da história original, em que o caçador era o salvador, na nova situação, ele é convertido a mau, caracterizado pelo fingimento de boa ação até $o$ ataque impetuoso à menina.

O lobo, por sua vez, nesse novo contexto, é o salvador da história, é quem leva a menina até a casa da sua avó, cujo caminho ele já conhecia, uma vez que, na outra história, ele foi acusado de ter atacado a avó e a Chapeuzinho. No final, há também uma moral que transporta todos os sentidos construídos, mas, sobretudo, o da denúncia sobre a confiabilidade no homem, mais especificamente, a confiabilidade em uma autoridade (o caçador), cuja função deveria ser proteger e não fazer o mal, mas que, nesta versão, reflete a construção de uma verdade da/pela escrevente.

O dado possibilita a percepção de como a atividade de leitura literária, que antecedeu a escrita, auxiliou na reflexão e na articulação do lido para recontextualizar uma nova história. A leitura do texto literário, possivelmente, fez refletir sobre a relação ideológica da mulher. Na história antiga, ela era aconselhada a não sair de casa, não se desviar do caminho para não atrair o lobo. Neste novo contexto, a personagem Chapeuzinho decide seu caminho, mesmo correndo riscos, e o lobo não mais a influencia. E se descobre que, nem sempre, são os temidos os mais perigosos, pois há, muitas vezes, "os lobos em pele de cordeiro".

Em relação aos aspectos linguísticos trabalhados em aula e recontextualizados pela escrevente, visualizamos a sequência de acontecimentos, compatível com a de um conto, que é tecido com progressão e lógica em sua textualidade: inicia com o pretérito imperfeito clichê de "era uma vez"; o enredo se inicia com a personagem principal saindo de casa; o cenário onde tudo acontece é em uma 
Recontextualização a serviço do desenvolvimento da escrita: análise de duas...

floresta; há um animal que é personificado e um herói; e a personagem principal vence os obstáculos desde a saída de sua casa.

O uso de aspas, para marcar os diálogos, também é reflexo do que foi abordado/estudado em sala de aula. A escolha do título é reveladora da construção do narrador onisciente. É como se a escrevente, para construí-lo, tivesse sido realmente uma espectadora do acontecimento relatado, dada a aversão revelada e expressa por meio da palavra "maldito".

A respeito das expressões referenciais escolhidas, podemos destacar que, no início, a personagem principal é referida como Chapeuzinho Vermelho e retomada pelo pronome ela. Só depois, quando Chapeuzinho se encontra com o caçador, é que a expressão referencial menina passa a caracterizá-la. E, ao caçador, é acrescentado o adjetivo "maldito" logo após o momento em que ele tenta violentar a menina. Já o lobo, segundo o caçador, era perigoso, mas passa a ser referido como senhor lobo, marcando a familiaridade e o "respeito" que a narradora já tinha por ele, principalmente quando ele aparece para salvar a menina.

A produção analisada é um exemplo do repertório que o trabalho com a leitura literária reflexiva oferece para agir sobre o mundo por meio da linguagem. Na história antiga, contada por Charles Perrault, ela era aconselhada a não sair de casa, não se desviar do trajeto para não atrair o lobo. Nesse novo contexto, a personagem Chapeuzinho decide seu caminho, e não mais o lobo a influencia, mesmo correndo riscos, e descobre-se que nem sempre são os temidos os mais perigosos, mas, muitas vezes, "os lobos em pele de cordeiro". O final, quando a menina percebe que o perigo não era o lobo, e sim o homem, mostra-se filosófico, principalmente, se pensamos no intertexto (que pode ter relação direta ou não) que essa escrita faz com "o homem é o lobo do homem", de Thomas Hobbes.

A reflexão sobre a questão social da mulher, que vemos implícita nesse conto, só foi possível graças à leitura e à possibilidade de deixar a estudante expor seu ponto de vista, recontextualizar sua percepção sobre a questão e, assim, situar-se como sujeito, tomando uma nova posição.

O processo de recontextualizar, assim, cumpre-se plenamente, ao resultar em um texto verossímil, de modo que se alterou "o ponto de vista perceptual, conceitual e/ou emocional por meio do qual uma dada situação é percebida, para deslocá-la a outro contexto que se adapta igualmente bem ou ainda melhor aos 'fatos' concretos da situação, e que irá alterar todo seu significado" (WATZLAWICK apud 
KOURILSKY-BELLIARD, 2004, p. 51), propiciando que a prática escolar de escrita se revelasse, naquele momento, como acontecimento discursivo (CORRÊA, 2007).

\section{POR FIM, AS CONSIDERAÇÕES}

Tanto o texto Chapeuzinho do brow, quanto $O$ maldito caçador revelam realidades cotidianamente "comuns" e singulares a cada escrevente, tendo eles vislumbrado, na atividade de recontextualizar, mais do que uma tarefa escolar: aproveitaram-se desse espaço para relatar pontos de vista, ideologias e acontecimentos. Isso se torna importante na medida em que o professor também passa a ver a produção textual a partir do conteúdo discursivo, dos ditos (e não ditos) no texto, e percebe o quanto de sentido é possível captar nessa materialidade que, na tradição do ensino de língua materna, é vista apenas estruturalmente, como um conjunto de elementos coesivos, como texto de aprendiz, a ser adequado a certo padrão.

O desenvolvimento da pesquisa-ação possibilitou deslocar os estudantes do lugar daqueles que "não escreviam, nem liam", para o lugar de estudantes atentos, ativos e interessados. À medida que se envolveram nas aulas de leitura, tiveram interesse em construir a própria narrativa, fato confirmado pelos resultados não previstos pela professora em serviço: a maioria dos estudantes entregou e reelaborou suas atividades. A escrita, nessa experiência, para além de um exercício de adequação, revela-se como atividade social reflexiva, e o conto de fadas, como um gênero catalisador (SIGNORINI, 2006). Em outras palavras, a escrita evidencia-se como um meio pelo qual os estudantes fazem aparecer suas vozes na relação com o mundo, (re)construindo os eventos sociais de acordo com sua visão.

A sequência de atividades de leitura, de interpretação e de análise linguística, mais a atividade de escrita, somada à socialização dos textos, propiciou que os estudantes se deslocassem dos lugares daqueles "que não escrevem", ou que "não sabem escrever", para o lugar daqueles que "têm muito a dizer por escrito". E o mais importante: modificou o agir da professora em serviço, que acompanhou todo o processo e se transformou com os resultados observados. Incluiu o trabalho de leitura de contos e da recontextualização no rol de suas atividades no ensino médio.

Os contos recontextualizados refratam tanto experiências empíricas quanto simbólicas (CORRÊA, 2004) e marcam ideologias, crenças e valores. A atividade de recontextualização contribuiu para o desenvolvimento de uma escrita significativa, eco das vozes dos aprendizes: "conjunção entre o material linguístico e 
Recontextualização a serviço do desenvolvimento da escrita: análise de duas...

os aspectos sócio históricos que ele guarda" (CORRÊA, 2007, p. 206, destaques nossos). Apostamos que estes (e não aqueles) é que devem vir em primeiro plano para o sucesso do trabalho com escrita na escola.

\section{REFERENCIAS}

AGUIAR, V. T. de (Coord.). Era uma vez... na escola: formando educadores para formar leitores. Belo Horizonte: Formato, 2001.

APARÍCIO, A. S. M. Análise linguística na sala de aula: modos de construir um percurso de investigação. In: GONÇALVES, A. V; SILVA, W. R; GÓIS, M. L. S. (Org.). Viabilizar a Linguística Aplicada: abordagens teóricas e metodológicas. São Paulo: Pontes, 2014.

BAKHTIN, M. Estética da criação verbal. São Paulo: Martins Fontes, 1997 [1929].

BAKHTIN, M. Marxismo e filosofia da linguagem. São Paulo: Hucitec, 2006 [1953].

BETTELHEIM, B. A psicanálise dos contos de fada. São Paulo: Paz e Terra, 2007.

BRASIL. Ministério da Educação. Parâmetros curriculares nacionais - Ensino Médio, Brasília: MEC, 2006.

COELHO, N. O conto de fadas - símbolos mitos e arquétipos. São Paulo: Ática, 1998.

CORDEIRO, G. S. Escrita de textos argumentativos em classes suíças francófonas do Ensino Médio: uma análise multifocal do objeto ensinado. Raído, Dourados, MS, v. 9, n. 18, jan./jun. 2015.

CORRÊA, M. L. G. O modo heterogêneo de constituição da escrita. SP: Martins Fontes, 2004.

CORRÊA, M. L. G. Pressupostos teóricos para o ensino da escrita: entre a adequação e o acontecimento. Filologia e Linguística Portuguesa, São Paulo, n. 9, p. 201-211, 2007.

DIAS, R. E. Competências - um conceito recontextualizado no currículo para a formação de professores no Brasil. Dissertação (Mestrado) - Universidade Federal do Rio de Janeiro-UFRJ, Rio de Janeiro, 2002.

DIAS, R. E. A recontextualização do conceito de competências no currículo de formação de professores no Brasil. TEIAS, Rio de Janeiro, ano 5, n. 9-10, jan./dez. 2004.

GÓES, L. P. Introdução à Literatura infantil e juvenil. 2. ed. São Paulo: Pioneira, 1991, 189 p.

KOURILSKY-BELLIARD, F. Recontextualização, uma importante etapa da mudança. In: KOURILSKY-BELLIARD, F. Do desejo ao prazer de mudar. SP: Manole, 2004. p. 49-62.

LIRA, B. C. Leitura e recontextualização: o discurso multimodal. São Paulo: Paulinas, 2010.

MOTTA-ROTH, D. Sistemas de gêneros e recontextualização da ciência na mídia eletrônica. Niterói, n. 28, p. 153-174, 1. sem. 2010.

PROPP, V. Morfologia do conto maravilhoso. Tradução de Jasna Paravich Sarhan. 2. ed. Rio de Janeiro: Forense Universitária, 2006.

SIGNORINI, I. Construindo com a escrita outras cenas de fala. In: SIGNORINI, I. Investigando a relação oral/escrito. Campinas, SP: Mercado de Letras, 2001.

SIGNORINI, I. (Org.) Gêneros catalisadores: letramento e formação do professor. São Paulo: Parábola, 2006.

TODOROV, T. As estruturas narrativas. 2. ed. São Paulo: Perspectiva, 1970. 
SOBRE AS AUTORAS

Tailane Flores Antunes é graduada em Letras pela Universidade Federal da Grande Dourados - UFGD (2015) e Mestre em Linguística Aplicada pela UFGD (2017). Atualmente atua como professora de Língua Portuguesa e Literatura em uma Escola Pública Estadual no distrito da cidade de Ponta Porã.

E-mail: tailaneflores@hotmail.com.

Edilaine Buin é graduada em Letras (Universidade Estadual de Campinas), tem Mestrado em Linguística (Universidade Estadual de Campinas) e Doutorado em Linguística (Universidade Estadual de Campinas). É professora/pesquisadora da Universidade Federal da Grande Dourados. Tem experiência na área de Linguística Aplicada, com pesquisa nos seguintes temas: Aquisição da Escrita, Letramentos e Formação de Professores.

E-mail: edilainebuin@ufgd.edu.br.

Recebido em 03 de jultho de 2017 e aprovado em 27 de maio de 2018. 